\title{
O Kitsch e a Crítica Social de Pedro Almodóvar: Uma análise através do figurino do filme Volver ${ }^{1}$
}

\section{Pedro Almodóvar's Kitsch and Social Criticism: An analysis through costume design in the film Volver}

DOI: $10.46814 /$ lajdv4n1-011

Recebimento dos originais: 01/01/2021

Aceitação para publicação: 28/02/2022

\author{
Ana Paula Kwitko \\ Doutoranda en Comunicación Audiovisual \\ Publicidad en la Universitat Autónoma de Barcelona - Espanha, \\ E-mail: apaula.poa@gmail.com
}

\section{RESUMO}

A proposta do presente artigo é analisar as relações e estratégias comunicacionais desempenhadas pelo elemento kitsch na narrativa cinematográfica do diretor espanhol Pedro Almodóvar. A ideia é tentar compreender como o figurino constrói um sistema que incorpora e comunica significados às obras do cineasta, já que o kitsch, em linhas gerais, é a arte da imitação de comportamentos e gostos burgueses, e essa cópia conota a busca pela igualdade social. A investigação, portanto, tem como foco de interesse as estratégias comunicacionais, estéticas e estilísticas do kitsch no filme Volver.

Palavras-Chave: Cinema, Pedro Almodóvar, kitsch, figurino, estratégias comunicacionais.

\begin{abstract}
The purpose of this paper is to analyze the relationships and communication strategies played by the kitsch element in the cinematographic narrative of Spanish director Pedro Almodóvar. The idea is to try to understand how the costumes build a system that incorporates and communicates meanings to the filmmaker's works, since kitsch, in general, is the art of imitating bourgeois behavior and tastes, and this copy connotes the search for social equality. The investigation, therefore, focuses on the communicational, aesthetic, and stylistic strategies of kitsch in the film Volver.
\end{abstract}

Keywords: Cinema, Pedro Almodóvar, kitsch, costume, communicational strategies.

\section{INTRODUÇÃO}

A construção de um objeto de pesquisa no campo da Comunicação abarca, além da abordagem multidisciplinar e do apoio de diversas correntes teóricas, o que alguns autores denominam de "olhar comunicacional". Um objeto de pesquisa que pode ser chamado de comunicacional é aquele que permite estudar como a linguagem, ao aproximar diferentes interlocutores (um cineasta e seu público,

\footnotetext{
${ }^{1}$ Trabalho apresentado no GP Cinema do XI Encontro dos Grupos de Pesquisa em Comunicação, evento componente do XXXIV Congresso Brasileiro de Ciências da Comunicação.
} 
por exemplo), pode não só estabelecer uma situação interativa, mas também produzir um acontecimento inusitado, que permita encontrar um universo que só pode ser apreendido por meio de uma interpretação que relaciona seus diferentes elementos textuais.

Com este entendimento, no presente artigo, o figurino cinematográfico é visto como um objeto de linguagem, um lugar de representação, uma forma de narração e uma unidade comunicativa. $\mathrm{O}$ trabalho tem por objetivo apresentar o entrelaçamento entre o figurino e a crítica social do cineasta espanhol Pedro Almodóvar. Para tanto, o escopo de estudo está centrado na filmografia do diretor e em sua forma peculiar de representação por meio do kitsch, um elemento já consagrado em sua estética. É realizada uma análise histórica do uso do kitsch em sua obra, sobretudo, na construção do figurino de seus personagens, na tentativa de melhor compreendermos o papel das vestimentas em sua narrativa.

\section{O KITSCH NA NARRAÇÃO ALMODOVARIANA}

Enquanto em Nova Iorque o estilo kitsch era coroado por artistas como Andy Warhol e Roy Lichtenstein, em Madri, quem mais o representava era Pedro Almodóvar. Ele foi o artista que melhor se valeu do kitsch genuinamente espanhol em seus trabalhos, o chamado cursi, que ajudou a compor sua tão reconhecida estética visual. Almodóvar representou, no cinema espanhol, o mesmo que Warhol na pintura e Lichtenstein no desenho.

O termo cursi, que tem o mesmo significado que kitsch, possui um sentido ético no espanhol e um sentido estético no alemão. Conforme explica Lídia Santos (2001, p. 97) "Lo kitsch como problema social e histórico aparece por primera vez en la cultura española, ya que la palabra castellana para designar el fenómeno - cursi - posee esa carga semántica en su propia etimología”. O kitsch é a cópia de obras e objetos artísticos pertencentes à cultura erudita produzidos em série, para o consumo do grande público. Bem como o kitsch, o cursi da Espanha é a arte da imitação de comportamentos e gostos burgueses, e essa cópia conota a busca pela igualdade social. É o que Santos chama de uma "metáfora de antropofagia", onde a massa absorve os códigos da elite e os reinterpreta.

Durante o final dos anos 1970 e início dos anos 1980, com a queda do franquismo, Madri teve um grande boom das artes que se assemelhou ao pop americano e que culminou em um movimento artístico chamado La Movida. Legatária da pop art reuniu as mais diversas expressões artísticas na época, todas subversivas, em oposição ao ordinário e espelhando as manifestações americanas contra os valores opressores de consumo de massa. Almodóvar viveu intensamente esse período cultural e levou para sua obra toda esta profusão de elementos que descrevem uma época.

El arte, la moda, la droga, la literatura, etc. están tan presentes tanto en Warhol como en Almodóvar, en los años 60 y 70 en Nueva York, y en los 70 y 80 en Madrid. Ambos de 
procedencia proletaria, quedaron para siempre adscritos a un mundo urbano que nunca abandonaron (HOLGUÍN, 2006, p. 160).

O kitsch está em todos os filmes de Pedro Almodóvar e diz respeito à sua própria vivência, que faz um aglomerado de elementos para expressar seu interior. O kitsch está na sociedade espanhola, na profunda relação que Almodóvar sempre teve com a religião, o desejo e a mulher. Bem como o diretor mesmo apontou: "É nesse artifício que se podem projetar todas as intenções do cineasta" (apud STRAUSS, 2008, p. 34). Um artista que cresceu no pós-guerra, sob o domínio reacionário do franquismo, valeu-se do kitsch para, entre outras coisas, transmitir suas ideias sérias de maneira divertida.

Um elemento importante deve ser destacado acerca da influência de Buñuel sobre Almodóvar, a saber a combinação crítica e a insistência temática nas ligações entre religião e política. [...] O elemento religioso e teológico é, para o diretor, pura iconografia em seu cinema, um problema metafísico que não tem proposições em seus filmes. Utiliza-se só dos aparatos decorativos, deixando de lado o papel meramente alienador. Seu cinema adquire assim liberdade e modernidade, graças à influência também de Buñuel e Bergman, para os quais a existência de Deus é uma constante busca, bem como da influência kitsch, que trata o religioso de forma ambivalente, do sagrado ao profano (RODRIGUES, 2008, p. 28).

O kitsch é o excêntrico na obra de Almodóvar, está presente no figurino de seus personagens, composto por roupas e acessórios de cores, estampas e texturas vivas e extravagantes. No cenário, faz uso contrastante e exagerado de cores, objetos religiosos, estátuas, bibelôs, fotografias de personagens da Disney, altares, bichos de pelúcia, eletrodomésticos e móveis antigos, tudo para compor esse estilo bastante singular que possui. "El cine almodovariano, como testigo ocular de nuestro tiempo, se ha visto imbuido de esta parafernália" (HOLGUÍN, 2006, p. 113).

Os filmes Pepi, Luci, Bom y otras chicas del montón e Laberinto de pasiones apresentam muito bem toda uma época e a influência da pop art e do estilo kitsch no trabalho do cineasta, conforme ele mesmo explica:

\footnotetext{
Pepi, Luci, Bom permitiu que eu concretizasse minha relação com um gênero do qual sempre me senti muito próximo - o pop. Nesse caso concreto, trata-se do pop do fim dos anos 1970 , que era duro e corrosivo. O pop dos anos 1960, o dos primeiros filmes de Richard Lester e das comédias de Frank Tashlin, com personagens de donas-de-casa americanas - que Doris Day encarnou maravilhosamente -, esse pop muito mais ligeiro e anódino, abordei-o em seguida em Labirinto de paixões (apud STRAUSS, 2008, p. 33).
}

Nos fotogramas a seguir, do filme La ley del deseo, é possível encontrar diversos detalhes da cena que apontam para o kitsch e que merecem destaque. No altar que a personagem vivida por Carmen Maura tem em casa, o mais autêntico exemplo: a mistura de imagens religiosas com fotos de divas do cinema, pequenas estatuetas de personagens como o de Marilyn Monroe, bichos de pelúcia, souvenir e flores de plástico. Um verdadeiro empilhamento de objetos que a personagem cultua e que fazem 


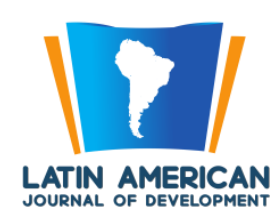

parte da sua história emocional de vida. Almodóvar pontua: “É isso, de modo preciso, que me interessa no cinema: algo que fala da realidade, que é verdadeiro, mas que, para ser perceptível, deve se tornar uma representação da realidade" (apud STRAUSS, 2008, p. 34).

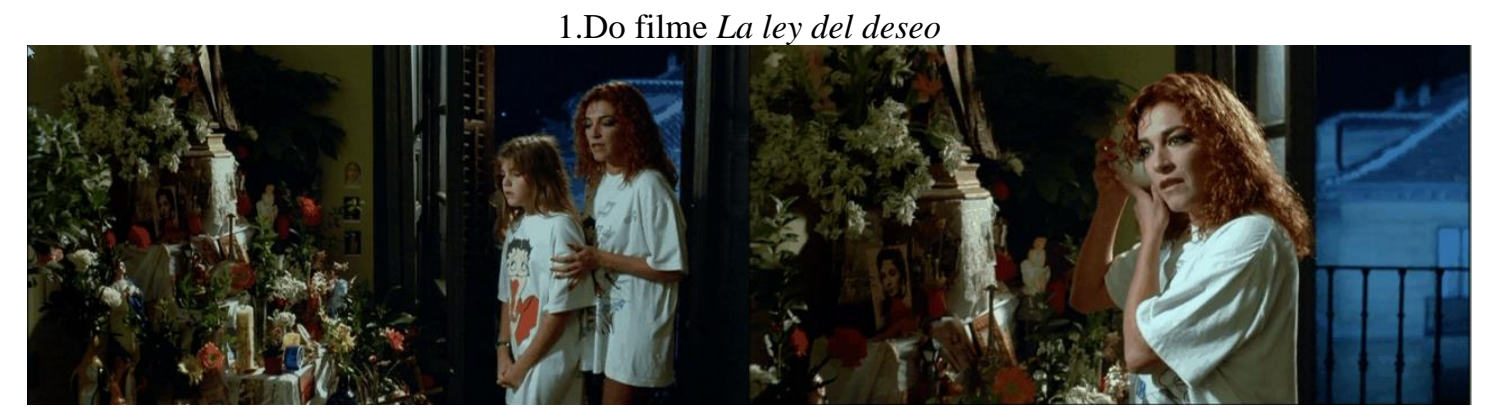

Outro detalhe do elemento kitsch está no figurino das duas personagens que vestem camisetas com foto de Betty Boop. Também é possível ver objetos kitsch como o jacaré porta-copo que está sobre a cama e o anjo na parede.

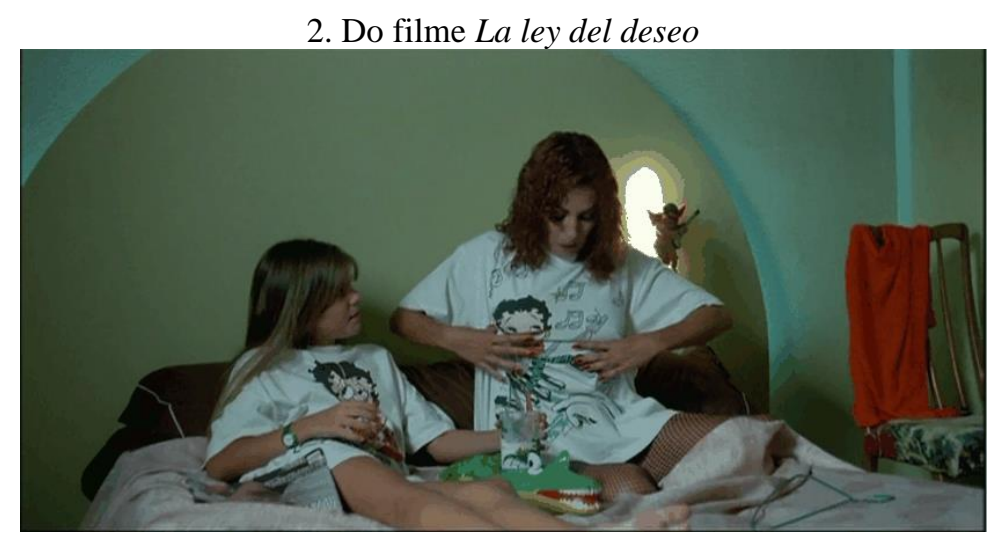

No primeiro fotograma a seguir, do filme Kika, aparecem elementos do kitsch como a imagem de uma santa ao fundo e fotografias de atrizes coladas na porta de um armário. O segundo fotograma é do filme La flor de mi secreto, em que aparece uma infinidade de objetos kitsch sobre a estante da casa da mãe da personagem Leo.

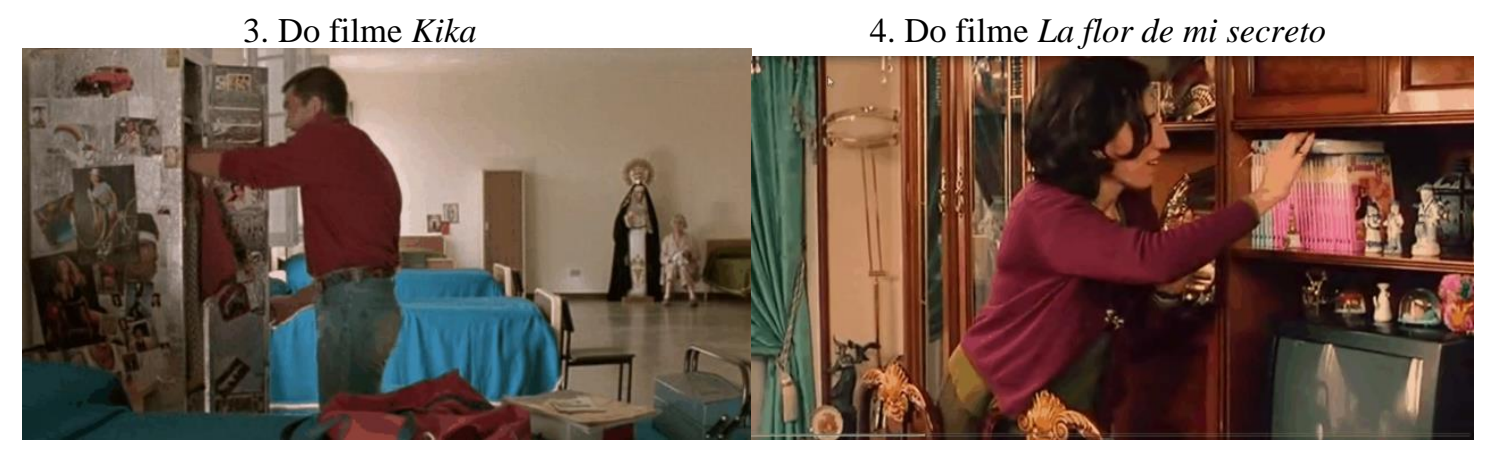


Nos fotogramas abaixo, ainda do filme La flor de mi secreto, é possível ver também a presença do kitsch no figurino da personagem Rosa, irmã de Leo, uma típica proletária que imita a irmã burguesa ao se vestir, e que acaba se tornando muito caricata, além de divertida por isso.
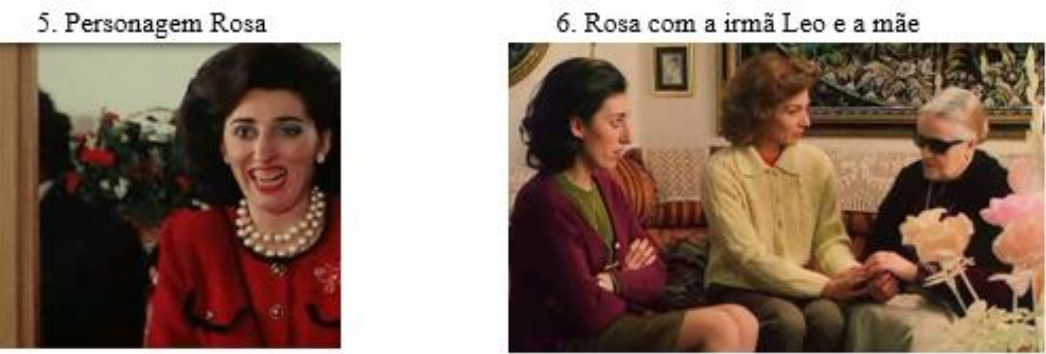

A seguir, fotogramas que demonstram muito bem o kitsch no trabalho de Almodóvar no filme Kika. Barbosa (1999, p. 62) explica:

[...] é seu monumento mais glorioso, no que se refere a este tema, toda produção de Kika. Ela é kitsch. Não há conceitos de bom ou mau gosto, tudo apenas está, compõe a cena verdadeiramente simples e eficaz. Pedro sabe como utilizar-se deste ícone; ele domina com leveza e grandiosidade, Kika é, em sua natureza, brega inocente, pudica, viva e sem malícias. Ela congrega objetos, pessoas e coisas, mistura tudo e acrescenta cores pelo simples prazer que isso lhe proporciona. Não há pecados, exageros culpas [...] Kika é Almodóvar.
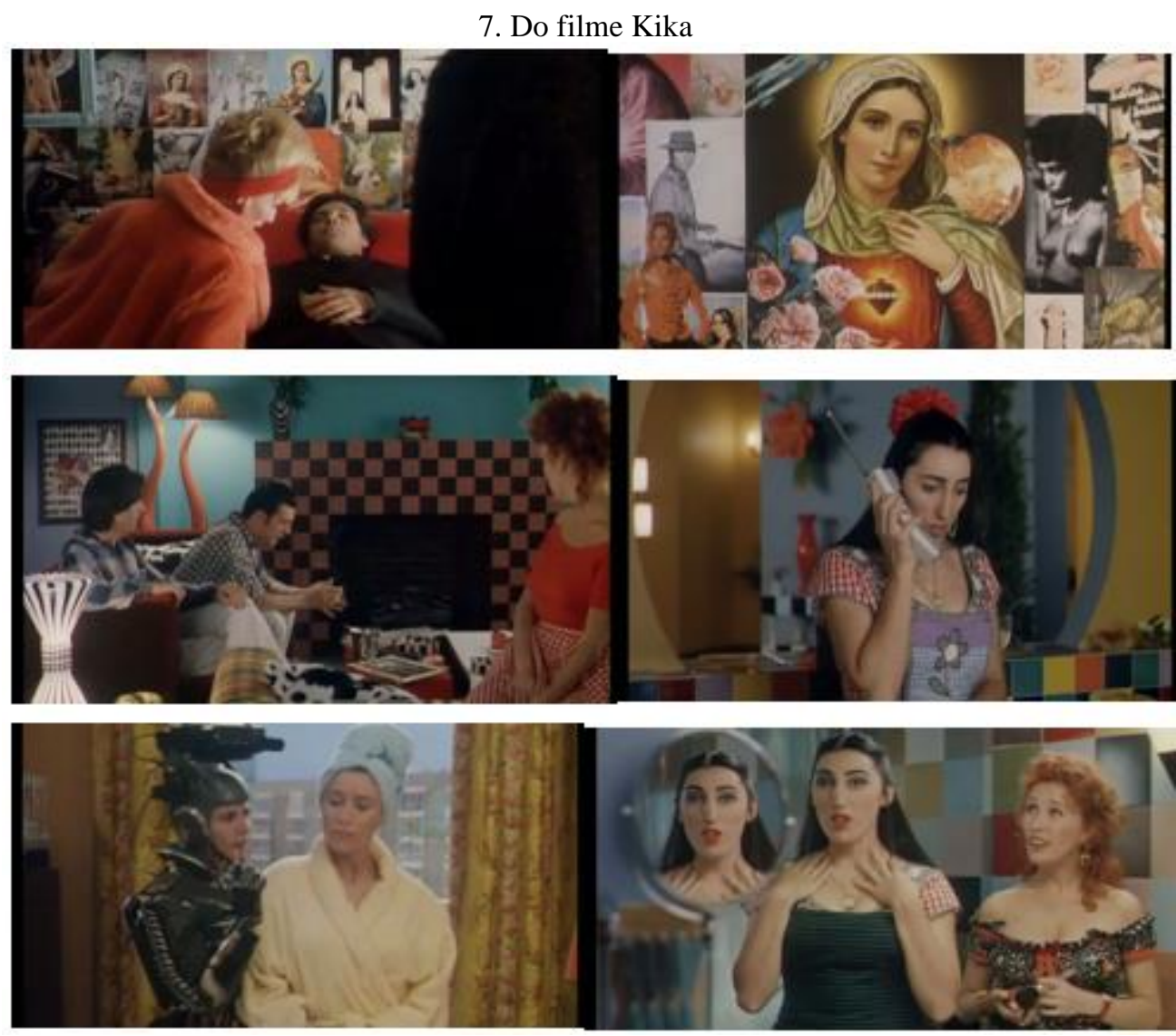


\section{O KITSCH EM VOLVER}

Volver é o relato de uma família narrado por três gerações de mulheres que foram maltratadas pela vida. O filme mostra um mundo feminino envolto numa atmosfera de narração cômico-dramática e kitsch, muito característica de Pedro Almodóvar. Mas passa a revelar uma nova fase no trabalho do diretor, que se difere em alguns pontos do que ele fazia até Carne trémula, conforme explica: “Ao longo desses últimos anos, vi-me mais confrontado com a solidão, e, portanto, mais voltado para mim mesmo. Isso teve uma influência sobre a minha inspiração, que se tornou mais introspectiva" (apud STRAUSS, 2008, p. 278).

Em Volver, Almodóvar olha para o passado e reencontra, nas lembranças da infância, as mulheres fortes e batalhadoras que, mesmo muito sofridas, são capazes ainda de serem engraçadas. $\mathrm{O}$ filme é um fechamento de ciclo na obra do diretor, e trata de um assunto que lhe diz respeito: a solidão.

É porque o que escrevo pertence à ficção, mas o que caracteriza as personagens dos meus filmes tem muito a ver com minha vida pessoal, minha maneira de viver. Não é um vínculo direto, evidente, mas é profundo. Transmiti então, de uma forma muito fértil, minha própria solidão às minhas personagens. [...] E o resultado é essa fase, provavelmente a mais interessante da minha filmografia até aqui [...] (apud STRAUSS, 2008, p. 278-279).

Almodóvar toma consciência da morte e da brevidade do tempo, e suas lembranças da infância emergem neste trabalho: as mulheres fortes e trágicas, a dor da solidão, a incompreensão da morte e o medo diante dela. Ele quis olhar para trás e entrar em contato com os mortos para estabelecer a mesma relação que as pessoas da sua aldeia tinham com eles, a de convivência natural e comum. A morte é, portanto, a questão essencial das personagens do seu filme e diz respeito à relação que as pessoas que viveram na infância tinham com ela, conforme conta o diretor: "Para você ter uma ideia, em todas as casas, deixa-se sempre uma vela acesa no cômodo da entrada, durante a noite, para o caso de algum morto voltar" (apud STRAUSS, 2008, p. 285).

É um filme essencialmente "manchego" - da região de La Mancha, Espanha - e emocional, ao provocar fantasias que dependem diretamente do texto - a mãe morta que nos retorna. "O surpreendente é que toda essa emoção está ligada à parte mais kitsch do filme, com aquele fantasma que retorna de uma comporta como uma pessoa normal” (apud STRAUSS, 2008, p. 290). 
8.Personagem Irene nas cenas que aparece para a filha Sole
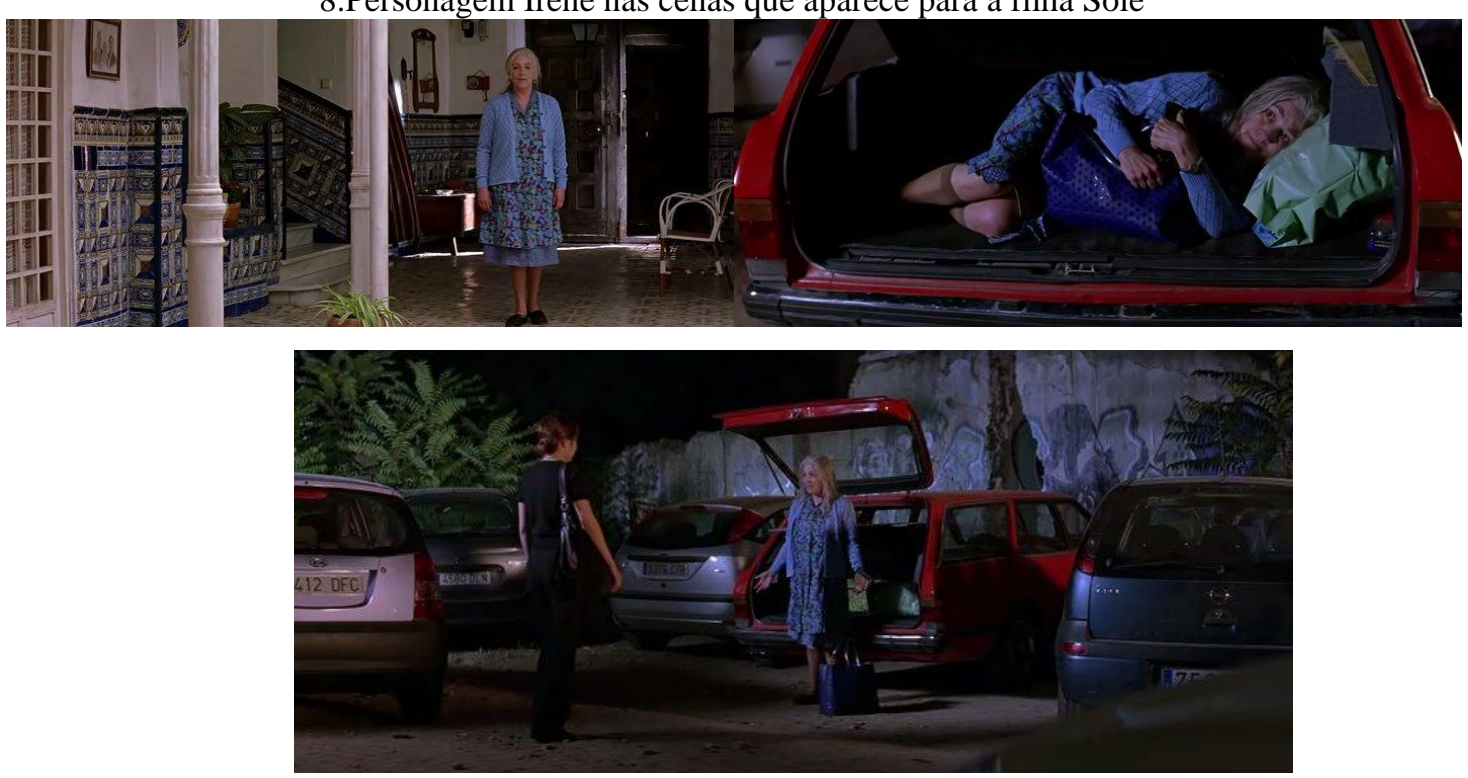

A ideia de ressuscitar seu passado para redescobrir sensações foi a principal razão para Almodóvar fazer o filme, diz Strauss. Ao retornar à La Mancha para as filmagens, reviu as mulheres que cuidam das sepulturas e as quis incorporar no filme; nenhuma delas é figurante e todas continuam iguais, vestindo-se da mesma maneira. $\mathrm{O}$ diretor quis vestir suas personagens com as mesmas nuances e quase todas revelam o kitsch espanhol em sua composição. Como aponta Holguín (2006, p. 308): "El vestuario es kitsch y rural, de mercadillo, como el de cualquier pueblo o aldea española".

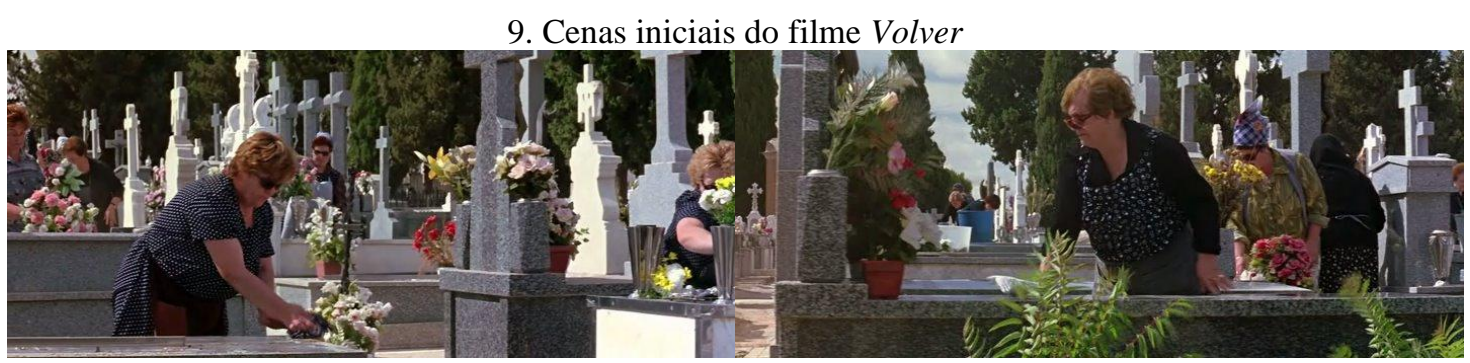

A partir de agora serão apresentados alguns dos fotogramas em que aparece o kitsch com mais força na narrativa de Volver, tanto as imagens como a própria simbologia da cena serão pontuadas. A seguir é apresentado o fotograma em que Irene e sua filha Raimunda se reconciliam. A mãe conta que só descobriu muito tarde que a filha era abusada sexualmente pelo pai, e que o matou para vingá-la. Nesta cena, Irene se veste como uma típica mulher do interior do seu país e que tem muito de kitsch, haja vista o uso das meias até os joelhos. A cena tem uma carga emotiva grande que se contrapõe ao cenário e figurino das personagens. 
10. Mãe e filha se reconciliam

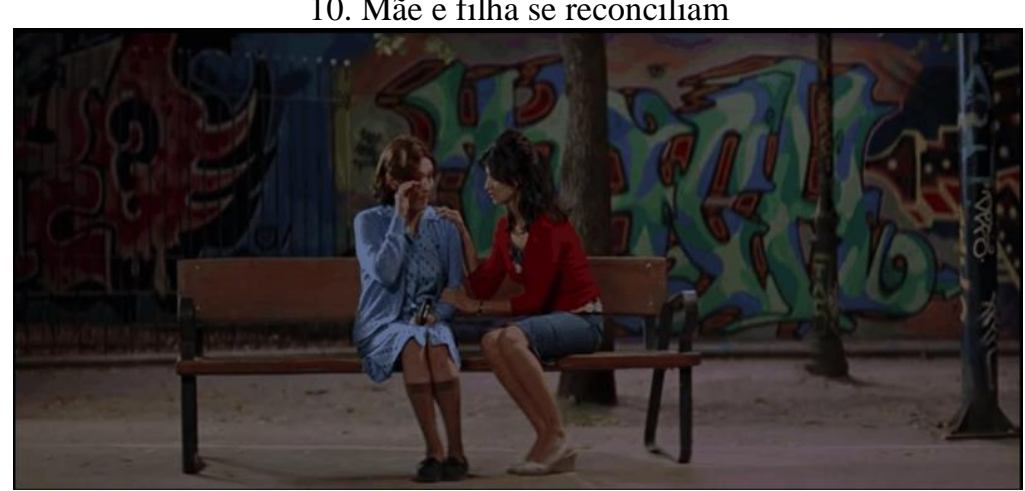

As roupas de todas as personagens mulheres têm alguns elementos que remetem ao kitsch, principalmente o de Raimunda, que usa muita estampa floral, combinada com xadrez e em cores intensas que vão do verde musgo ao roxo, conforme poderá ser visto nos fotogramas a seguir. Raimunda é uma mulher ancorada na sua dura realidade, foi estuprada e teve uma filha do pai; seu marido é um fracassado que também tenta abusar de sua filha; ela tem uma vida humilde, vive na periferia de Madri e precisa trabalhar muito para se manter com a filha adolescente. No entanto, ela se veste com esmero e é uma mulher bonita. "As mulheres fortes que lutam para viver, que são ao mesmo tempo trágicas e engraçadas, essas mulheres que estão em todos os meus filmes, vêm todas da minha infância” (apud STRAUSS, 2008, p. 283).

10. Figurino da personagem Raimunda: mistura de cores e estampas

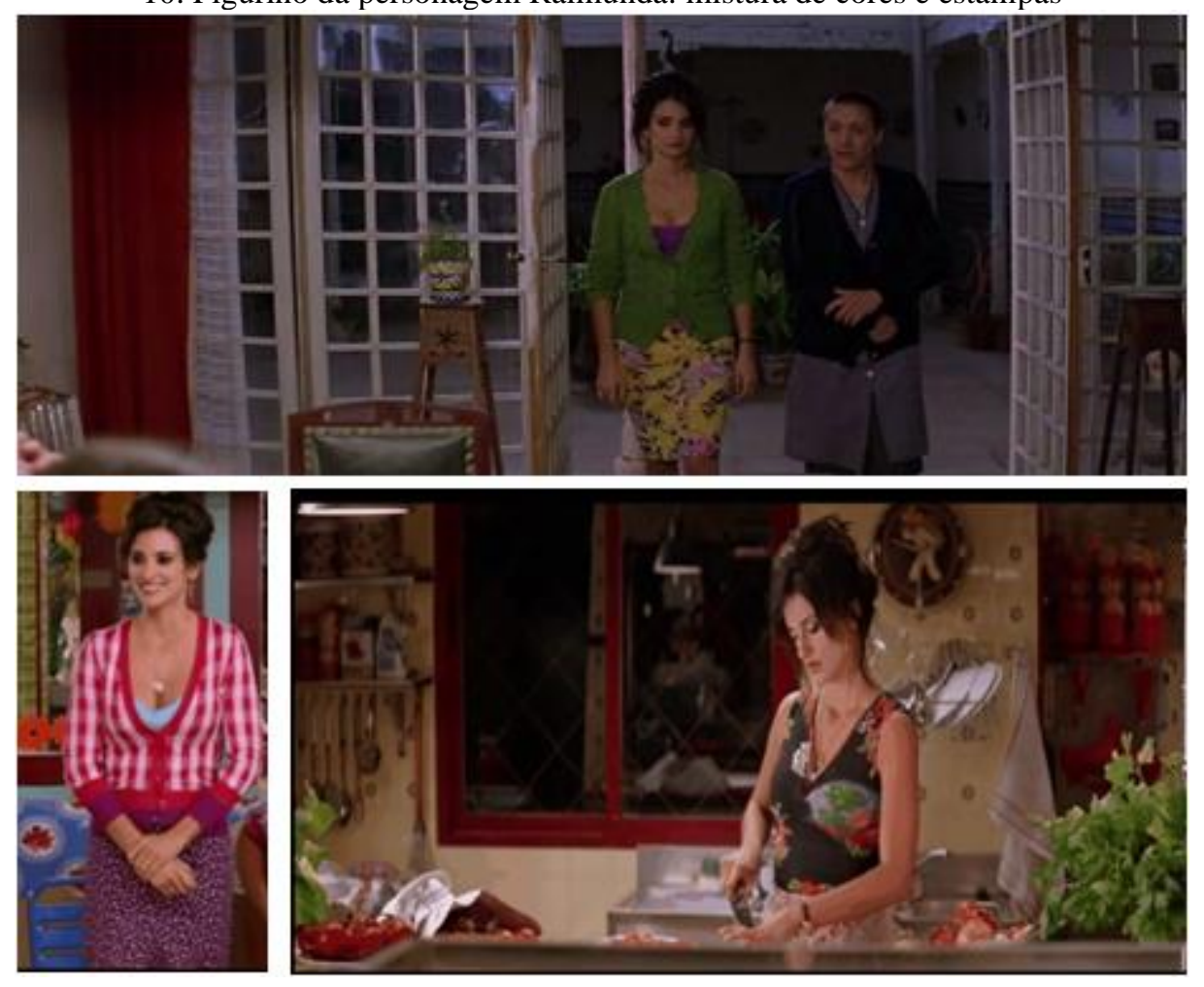


11. Detalhe da bolsa de Raimunda, uma imitação da marca Louis Vuitton
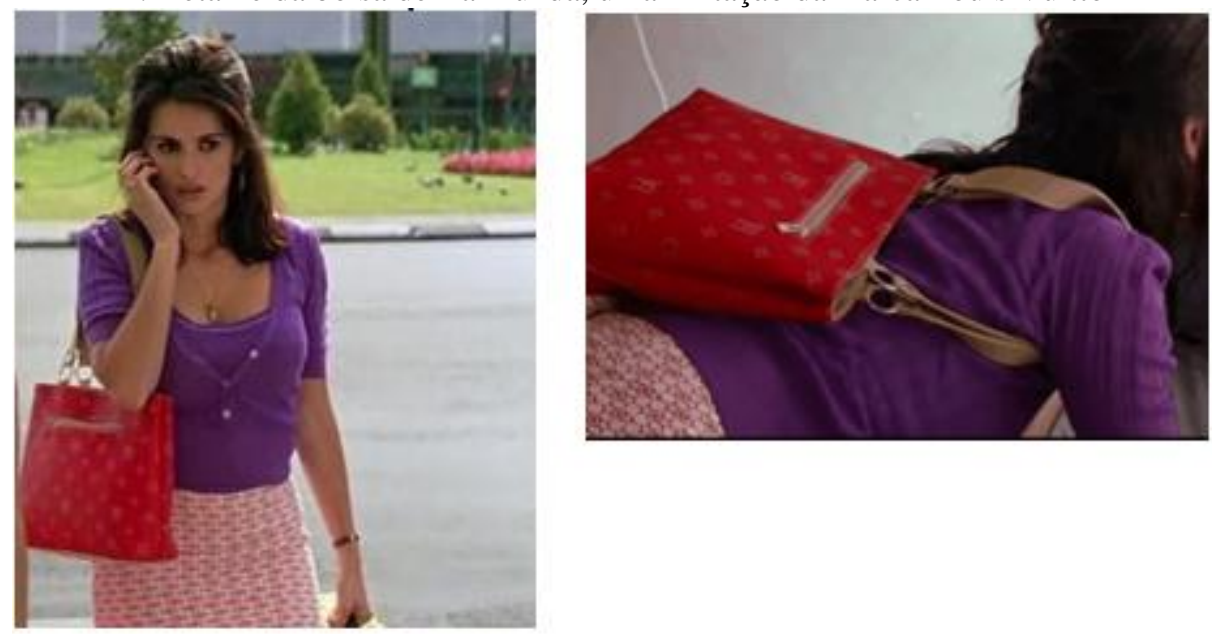

Raimunda chegando em casa, no subúrbio de Madri, de ônibus, com sacola do Carrefour, um dos grandes templos de consumo proletariado:
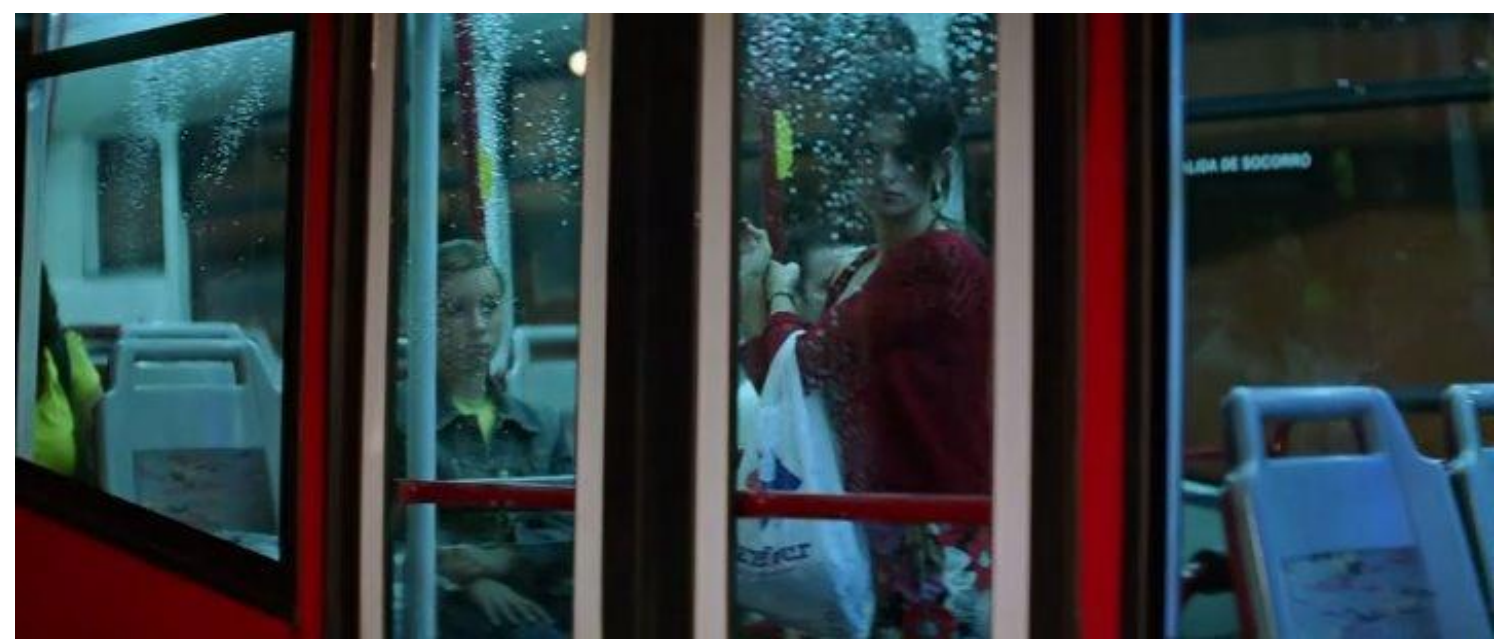

No fotograma abaixo, cena na casa de Raimunda e alguns exemplos de objetos kitsch: A "bola de neve" sobre a bancada azul e os sofás da sala feitos em madeira de pinus.

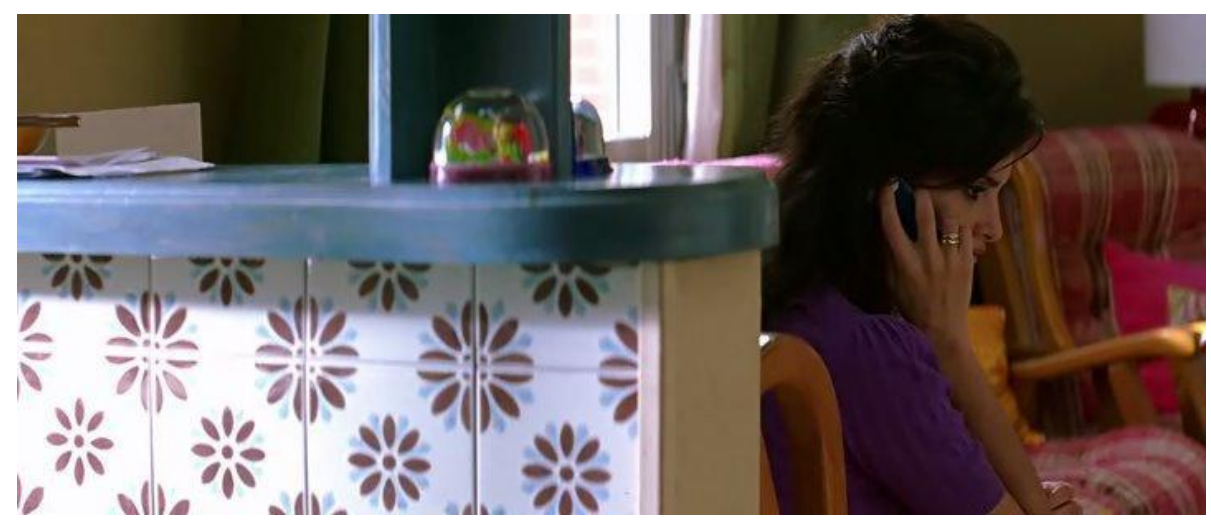


A personagem Sole também vive num universo muito kitsch: seu quarto é decorado com bonecas antigas, imagens religiosas, móveis de estilo antigo, a sua sala se transforma em salão de beleza, a cozinha possui uma infinidade de objetos, enfim, uma gama de elementos do kitsch e que compõem a personagem. Sole é uma mulher muito solitária, que foi abandonada pelo marido. Seu quarto é visto pelo espectador somente de longe, como se apenas uma parte de sua história amorosa pudesse ser revelada.

Outro elemento kitsch da personagem está na adaptação que ela faz do seu apartamento para manter seu salão de beleza clandestino.

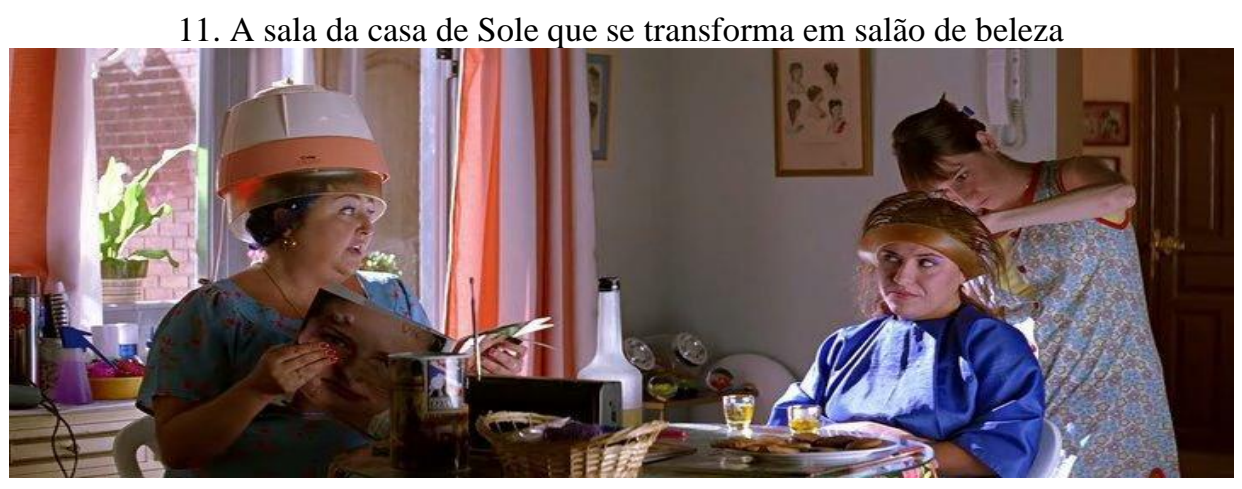

12. O quarto de Sole, que aparece ao fundo, possui um grupo de objetos kitsch: bonecas na cama, quadro de santo na parede, lustre e poltrona retrôs

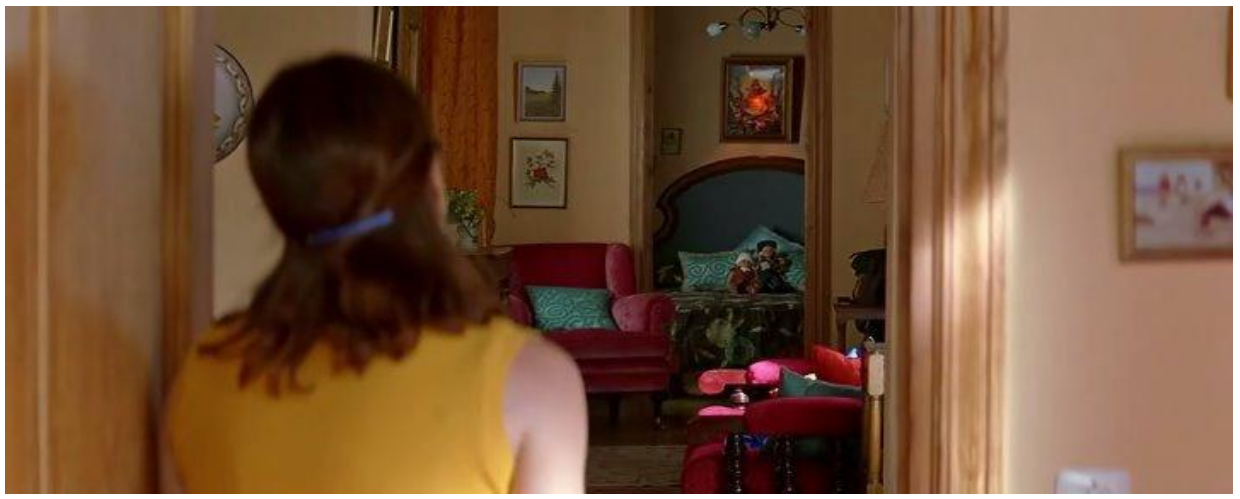

13. Sole mostra para a mãe como lavar a cabeça das clientes no seu banheiro

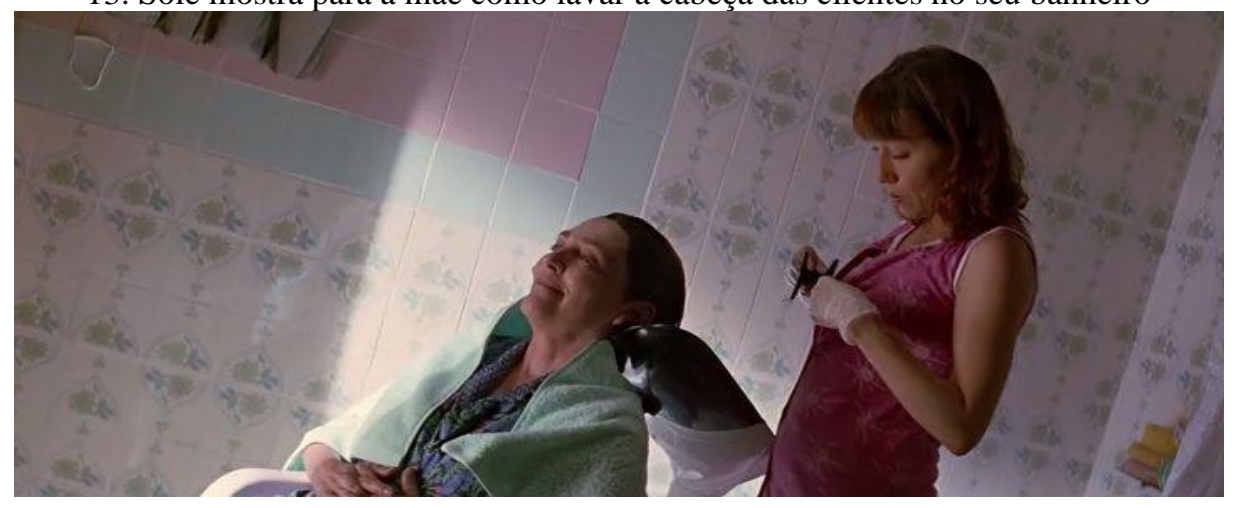




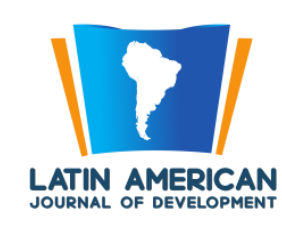

O kitsch no figurino também ficou bem marcado nas roupas da personagem amiga de Raimunda e que é prostituta, ela faz muitas misturas de estampas, cores e texturas ao se vestir. A presença de objetos kitsch é encontrada ainda na barraca que a personagem está trabalhando para vender bebidas.
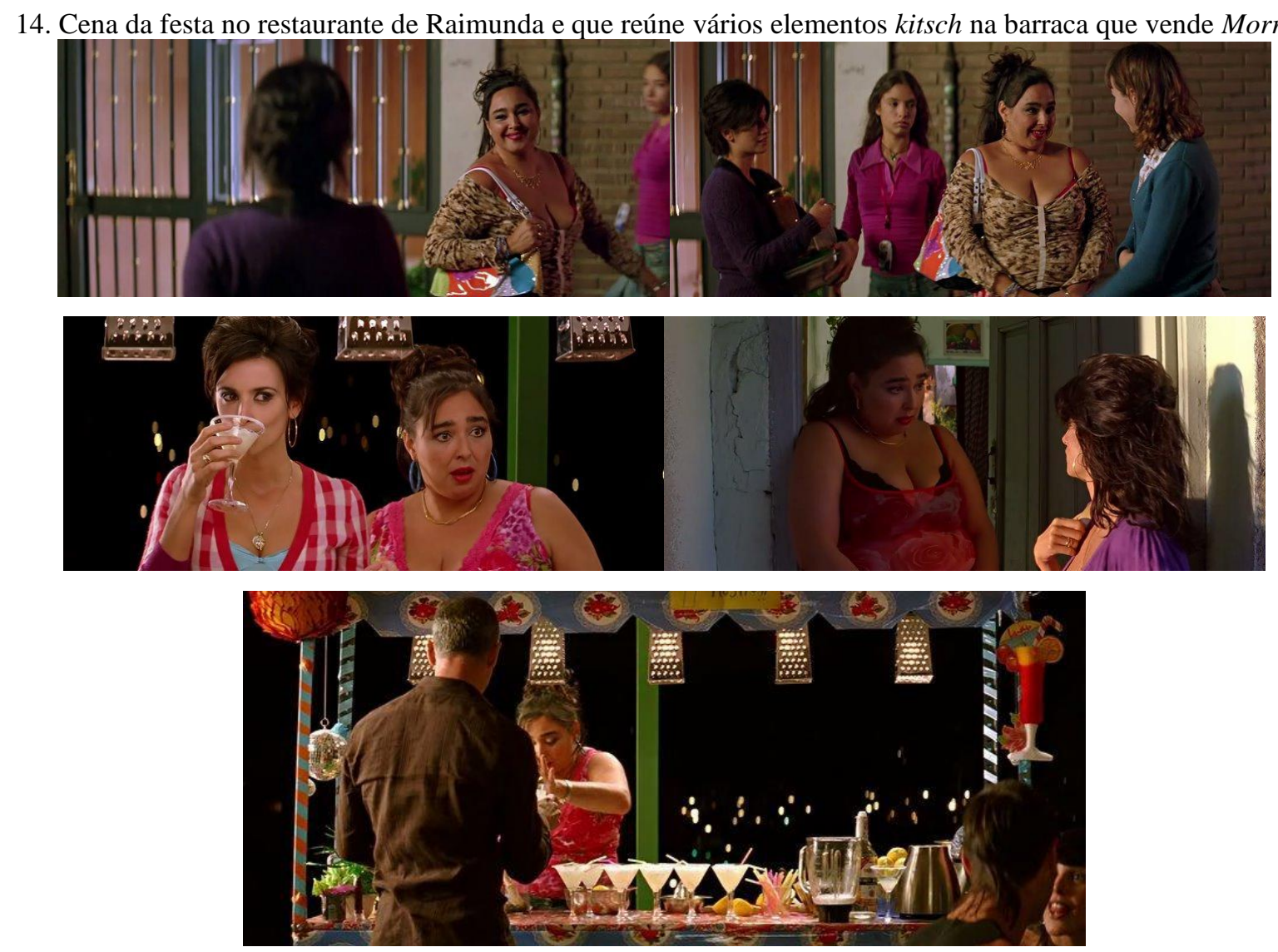

No que diz respeito ao figurino, as referências ao kitsch são muito mais claras quando Almodóvar vai fazer crítica à cultura de massa no programa de televisão em que Agustina dá entrevista. "Hay también una crítica a la televisión a través de un programa titulado $<$ Dondequiera que estés $>$, ejemplo de la telebasura que inunda la mayoría de las cadenas de televisión" (HOLGUín, 2008, p. 308). Em todo trabalho do diretor existe uma forte crítica à mídia e aqui ela está muito bem marcada pelos diálogos das personagens e sustentada pelo elemento kitsch do figurino.

15. Figurino da apresentadora com uma flor absolutamente kitsch

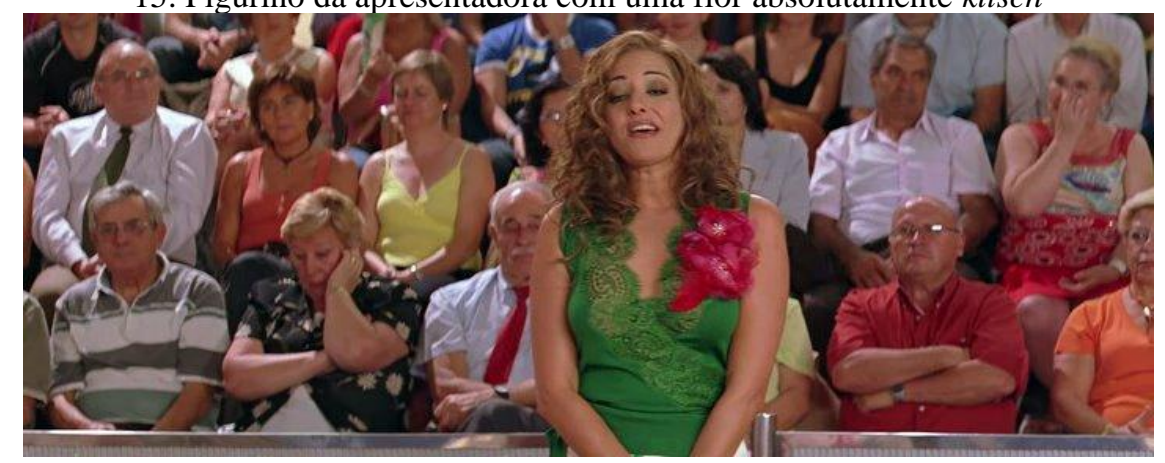


Agustina é uma mulher simples que vive no interior de Madri e está precisando de tratamento para o câncer, mas não tem recursos. Ela participa, por intermédio da irmã, de um programa de televisão sensacionalista, com o objetivo de encontrar a mãe que está sumida há quase três anos e também para ganhar um tratamento em Houston para sua doença. Só que em troca terá de se expor em frente às câmeras e contar a história da sua família, da mãe hippie, que era amante de um homem que morreu ao lado da esposa, curiosamente no mesmo dia em que desapareceu. Durante a entrevista, as pessoas riem quando Agustina diz que a mãe é hippie e batem palma ao saberem que tem câncer. Ela percebe que foi um engano ter concordado com aquele espetáculo e sai no meio do programa sem dar explicações.

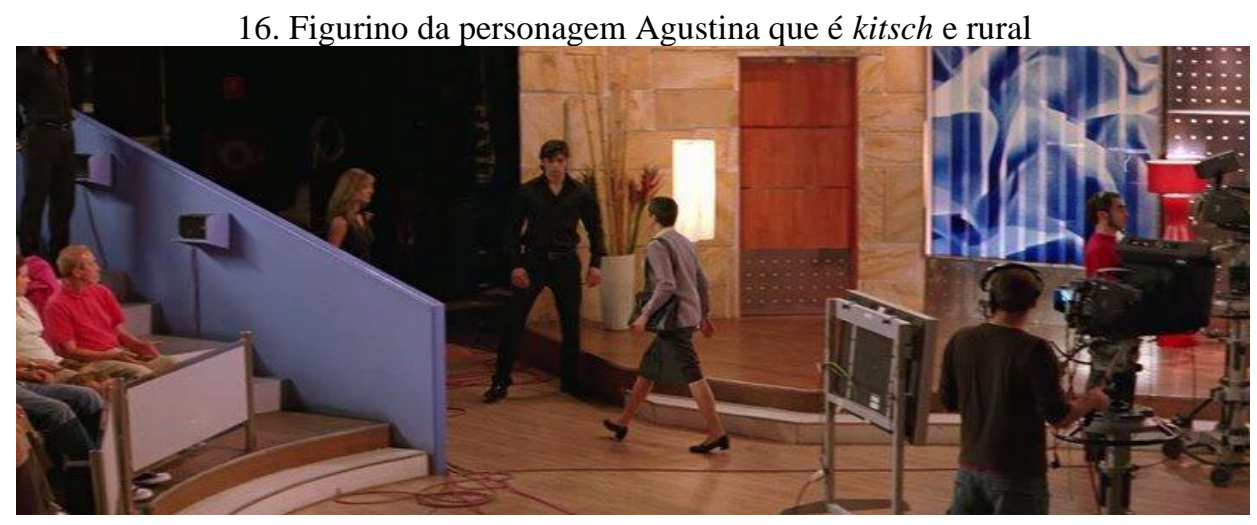

\section{CONSIDERAÇÕES FINAIS}

Almodóvar é um cineasta múltiplo, com influências artísticas que envolvem outros elementos além do kitsch, como o melodrama, o Neorrealismo e o comics. Neste trabalho, o foco recai apenas sobre a influência kitsch em sua filmografia.

A trajetória artística de Pedro Almodóvar, sua procedência e formação são indiscutivelmente as principais chaves para se entender sua narrativa. Seu olhar é repleto de conotações visuais, e sua narrativa se faz mais por descobertas icônicas que literárias. Em seus filmes, o figurino dispõe de uma linguagem tão sutil quanto complexa, capaz de expressar com grande habilidade não somente a personalidade, mas também a crítica social do diretor.

O figurino materializa o universo emocional de Almodóvar, e o faz infringindo a precisão realista e a probabilidade representativa da imagem, dispondo de um conjunto rico de artifícios expressivos mais ou menos simbólicos da interioridade das personagens. As vestes de uma personagem são como artifícios codificados, elementos simbólicos sob particularidades de formas e cores, e apontam para uma complexa linguagem visual que expressa o que o diretor pretende em sua narrativa.

Neste trabalho, olha-se para o figurino como quem vê um texto, ou melhor, uma narrativa que conta uma história paralela àquela desenrolada no filme. Ele é entendido como uma linguagem que se 
apresenta em diferentes estilos e códigos. Um arranjo estético que possui elementos em sua composição não colocados somente como adornos e enfeites, mas que são operantes e possuem funções claras e definidas na narrativa. O figurino é uma linguagem que narra algo sobre um determinado personagem, dando origem a uma dinâmica discursiva que coloca em relação produtores, história e espectadores.

O estudo do kitsch no figurino de Almodóvar revela o forte apelo social deste elemento, que vai desde a distinção de classes à representação da sexualidade. Seu trabalho é um mecanismo, uma técnica que se transforma em elementos de identificação do social. 


\section{REFERÊNCIAS}

BARBoSA, J. C. A estética do cineasta espanhol Pedro Almodóvar: Almodóvar o touro indomável. Dissertação de mestrado - Faculdade Cásper Líbero, São Paulo, 1999.

HOLGUín, A. Pedro Almodóvar. Madrid: Ediciones Cátedra, 2006.

RODRIGUES, A. L. Pedro Almodóvar e a feminilidade. São Paulo: Escuta, 2008.

SANTOS, L. Kitsch Tropical: los medios en la literatura y el arte en America Latina. Madrid: Iberoamericana, 2001.

STRAUSS, F. Conversas com Almodóvar. Rio de Janeiro: Jorge Zahar, 2008.

Trabalho apresentado no GP Cinema do XI Encontro dos Grupos de Pesquisa em Comunicação, evento componente do XXXIV Congresso Brasileiro de Ciências da Comunicação.

Mestre em Comunicação na Contemporaneidade pela Faculdade Cásper Líbero - SP, email: HYPERLINK "mailto:apaula.poa@gmail.com" apaula.poa@gmail.com 